\title{
Bone Marrow-Derived Mononuclear Cells Promote Improvement in Glomerular Function in Rats with Early Diabetic Nephropathy
}

\author{
Raquel C. Castiglione ${ }^{a}$ Tatiana Maron-Gutierrez ${ }^{a, b}$ Carolina M.L. Barbosa ${ }^{a}$ \\ Felipe M. Ornellas ${ }^{a}$ André Luis Barreira ${ }^{c}$ Carolina B.A. diBarros ${ }^{d}$ \\ Andréia Vasconcelos-dos-Santos ${ }^{e}$ Bruno Diaz Paredes ${ }^{\dagger}$ Bernardo M. Pascarelli ${ }^{9}$ \\ Bruno L. Diaz ${ }^{\text {h }}$ Bartira Rossi-Bergmann ${ }^{d}$ Christina M. Takiya ${ }^{c}$ Patricia R.M. Rocco ${ }^{b}$ \\ Jackson Souza-Menezesi Marcelo M. Morales ${ }^{a}$
}

\begin{abstract}
aLaboratório de Fisiologia Celular e Molecular, Instituto de Biofísica Carlos Chagas Filho, Universidade Federal do Rio de Janeiro, Rio de Janeiro; 'Laboratório de Investigação Pulmonar, Instituto de Biofísica Carlos Chagas Filho, Universidade Federal do Rio de Janeiro, Rio de Janeiro; 'Laboratório de Patologia Celular, Instituto de Biofísica Carlos Chagas Filho, Universidade Federal do Rio de Janeiro, Rio de Janeiro; 'Laboratório de Imunofarmacologia, Instituto de Biofísica Carlos Chagas Filho, Universidade Federal do Rio de Janeiro, Rio de Janeiro; 'Laboratório de Neurobiologia Celular e Molecular, Instituto de Biofísica Carlos Chagas Filho, Universidade Federal do Rio de Janeiro, Rio de Janeiro; flaboratório de Cardiologia Celular e Molecular, Instituto de Biofísica Carlos Chagas Filho, Universidade Federal do Rio de Janeiro, Rio de Janeiro; 'Laboratório de Patologia, Instituto Oswaldo Cruz, Fundação Oswaldo Cruz, Rio de Janeiro; haboratório da Inflamação, Instituto de Biofísica Carlos Chagas Filho, Universidade Federal do Rio de Janeiro, Rio de Janeiro; 'Laboratório de Bioquímica Integrada Hatisaburo Masuda, Núcleo em Ecologia e Desenvolvimento Sócio-ambiental, Universidade Federal do Rio de Janeiro, Macaé 27971-220, RJ
\end{abstract}

\section{Key Words}

Bone marrow mononuclear cells - Diabetic nephropathy - Renal function - Arginase I+ macrophages $\cdot$ Cytokines

\footnotetext{
Abstract

Background/Aims: Diabetic nephropathy is one of the main causes of end-stage renal disease. The present study investigated the effect of mononuclear cell (MC) therapy in rats subjected to diabetic nephropathy. Methods: Male Wistar rats were divided into control (CTRL), diabetic (DM), CTRL+MC and DM+MC groups. Diabetes was induced by a single injection of streptozotocin (45 mg/kg, i.p.) and, 4 weeks later, $2 \times 10^{7} \mathrm{MCs}$ were injected via the jugular vein. Results: The rats in the DM and DM+MC groups showed increased glycemia, glomerular filtration rate and glomerular tuff area versus control groups. The glomerular filtration rate and glomerular tuff area were normalized in the $\mathrm{DM}+\mathrm{MC}$ group. No alterations were observed in the fractional excretion of electrolytes and proteinuria between the DM and DM+MC groups. 
TGF- $\beta 1$ protein levels in the DM group were significantly increased versus control animals and normalized in the DM+MC group. An increase in ED1 $1^{+} /$arginase $\mathrm{I}^{+}$macrophages and IL-10 renal expression was observed in the DM+MC group versus DM group. Conclusions: Bone marrow-derived $M C$ therapy was able to prevent glomerular alterations and TGF- $\beta 1$ protein overexpression and modulated glomerular arginase $\mathrm{I}^{+}$macrophage infiltration in rats subjected to early diabetic nephropathy.

Copyright $@ 2013$ S. Karger AG, Basel

\section{Introduction}

Diabetic nephropathy is one of the most serious complications of diabetes and the most common cause of end-stage renal failure in the western world [1,2]. The development of diabetic nephropathy is stimulated by prolonged hyperglycemia [3-6] and the disease has distinct phases of development. Early alterations include glomerular and tubular epithelial hypertrophy, glomerular hyperfiltration, and development of microalbuminuria. Progression of the renal disease is characterized by gradual thickening of the glomerular basement membrane accompanied by mesangial matrix expansion with accumulation of several matrix proteins, such as collagen fibers, laminin, and fibronectin. Advanced diabetic nephropathy is usually accompanied by hypertension and leads to a decrease in the glomerular filtration rate, reduction in the glomerular filtration surface area, glomerulosclerosis, proteinuria above $500 \mathrm{mg} / 24 \mathrm{~h}$ with macroalbuminuria, arteriolar hyalinosis, tubular atrophy, and tubulointerstitial fibrosis [2, 4, 7-9].

Multiple mechanisms might contribute to the development and progression of diabetic nephropathy, including (1) Amadori products and advanced glycated end products, (2) oxidative stress, (3) the effects of increased levels of glucose and its metabolites on cells, (4) increased activation of vasoactive factors, such as the vasoconstrictors angiotensin (Ang) II and endothelin, (5) increased activation of vasodilator factors such as nitric oxide, (6) stimulation of expression of cytokines and growth factors, and (7) accumulation of activated macrophages in kidneys associated with interleukin (IL)-6, IL-1 and platelet-derived growth factor secretion $[2,6,7,10-12]$.

Several authors have suggested that the transforming growth factor (TGF)- $\beta$ system plays an important role in the pathogenesis of diabetic nephropathy by stimulation of the synthesis of key extracellular matrix molecules including type I collagen [13], type IV collagen, fibronectin, and laminin, and by decreasing matrix degradation through inhibition of proteases and activation of protease inhibitors [14-16]. Almost all of the molecular mediators and intracellular signaling pathways that have been identified in diabetic kidney injury, such as high glucose, Amadori products, advanced glycated end products, and oxidative stress, have also been found to stimulate renal TGF- $\beta$ activity as an intermediary step in early and advanced stages of the disease [2].

Early detection of diabetic nephropathy, adoption of multifactorial interventions targeting the main risk factors (e.g., hyperglycemia and hypertension) and the use of agents with a renoprotective effect, such as renin-angiotensin system blockers, reduce the progression of renal disease $[8,17]$. However, despite the strategies mentioned above, approximately $40 \%$ of patients with type 1 diabetes who have diabetic nephropathy will go on to develop end-stage renal disease within a decade [7].

As bone marrow-derived mononuclear cells (MC) have already been successfully used as an experimental therapy in several organs and tissues, such as heart, liver, tendon, peripheral nervous system, and kidney [18-24], these cells might be an alternative to the existing prevention and treatment strategies for diabetic nephropathy. Thus, our aim was to investigate whether bone marrow-derived MCs might be used in the treatment of early stage diabetic nephropathy in rats. 


\section{Materials and Methods}

\section{Animal model}

This study was approved by the Ethics Committee of the Health Sciences Center, Federal University of Rio de Janeiro (protocol number IBCCF 074). Animals were obtained from Animal Service (Rat Session) Health Sciences Center of Federal University of Rio de Janeiro and received humane care in compliance with National Society for Medical Research and National Academy of Sciences guidelines for the care and use of animals. Surgeries were performed under sodium pentobarbital anesthesia, and all efforts were made to minimize suffering.

Male Wistar rats (180-230 g, 8-9 weeks old) were housed in a 12:12 h light/dark facility at room temperature $\left(21^{\circ} \mathrm{C}\right)$ with food and water provided ad libitum. No more than 3 animals were kept per cage during the experiments.

\section{Experimental design}

The animals were randomly assigned into 4 groups: control (CTRL), control treated with bone marrowderived MCs (CTRL+MC), diabetic (DM) and diabetic treated with bone marrow-derived MCs (DM+MC) (Fig. 1). CTRL and CTRL+MC animals received $0.5 \mathrm{ml}$ of citrate buffer (4.5 M, pH 4.7) intraperitoneally (i.p.) on the first day; DM and DM+MC animals received $45 \mathrm{mg} / \mathrm{kg}$ body weight (b.w.) of streptozotocin dissolved in citrate buffer (4.5 M, pH 4.7; $0.5 \mathrm{ml}$ i.p.). The rats were considered diabetic when 5-hour fasting blood glucose levels exceeded $250 \mathrm{mg} / \mathrm{dl}$ at 2 weeks after streptozotocin administration.

CTRL and DM animals also received sterile saline solution ( $0.9 \% \mathrm{NaCl}, 0.15 \mathrm{ml})$ via the left jugular vein 4 weeks after the beginning of the experiments and CTRL+MC and DM+MC animals received bone marrowderived MCs $\left(2 \times 10^{7}\right)$ in sterile saline solution $(0.9 \% \mathrm{NaCl}, 0.15 \mathrm{ml})$ via the left jugular at the same time point (Fig. 1).

Four weeks after the beginning of the experiments and before MC infusion, 6 animals from the CTRL group and 7 from the DM group were subjected to renal function analysis and then sacrificed under deep anesthesia and sedation with an intraperitoneal injection of ketamine (75 mg/kg b.w.) and xylazine (10 mg/ kg b.w.).

All the other animals from the CTRL, DM, CTRL+MC and DM+MC groups (13-15 animals per group) were followed for 16 weeks after the beginning of the experiments. Renal function was analyzed, the animals were sacrificed under deep anesthesia and sedation as described earlier and the kidneys were isolated for further analysis (Fig. 1).

Blood glucose and body weight measurements

A drop of tail blood was taken by making a small snip in the terminal $1.5 \mathrm{~mm}$ of the tail with a scalpel. Blood glucose concentration was determined using a OneTouch $\AA_{\text {Ultra }}{ }^{2}$ glucose meter (Lifescan, Inc., CA, USA). Before the start of the experiments, all animals were subjected to $5 \mathrm{~h}$ fasting followed by measurements of glycemia and body weight. The same measurements were repeated twice a week until the sacrifice.

Preparation of bone marrow-derived MCs

Bone marrow-derived cells from male Wistar rats (8-9 weeks old) were aspirated from the femur and tibia by flushing the bone marrow cavity with Dulbecco's modified Eagle's medium (Life Technologies, Grand Island, NY, USA). After a homogeneous cell suspension was achieved, the cells were centrifuged (400×g for $10 \mathrm{~min}$ ) and re-suspended in Dulbecco's modified Eagle's medium. To obtain bone marrowderived monoculear cells, this suspension was added to Ficoll-Hypaque (Histopaque 1083, Sigma Chemical Co., St. Louis, MO, USA) and again centrifuged. The monocluear phase was collected and supplemented with sterile phosphate-buffered saline (PBS). Cells were counted in a Neubauer chamber with Trypan Blue for evaluation of viability. The animals were anesthetized with sevoflurane for the administration of saline or MC. All surgical materials were sterilized.

\section{Analysis of metabolic data}

To analyze the renal function of the animals, $24 \mathrm{~h}$ before sacrifice ( 4 or 16 weeks after the beginning of the experiments) all animals were placed in individual metabolic cages for $19 \mathrm{~h}$ with free access to water and food and the last $5 \mathrm{~h}$ under fasting conditions with free access to water. The food and water 
Fig. 1. Timeline of the experimental protocol. CTRL, control group; DM, diabetic group; MC, bone marrow-derived mononuclear cells.

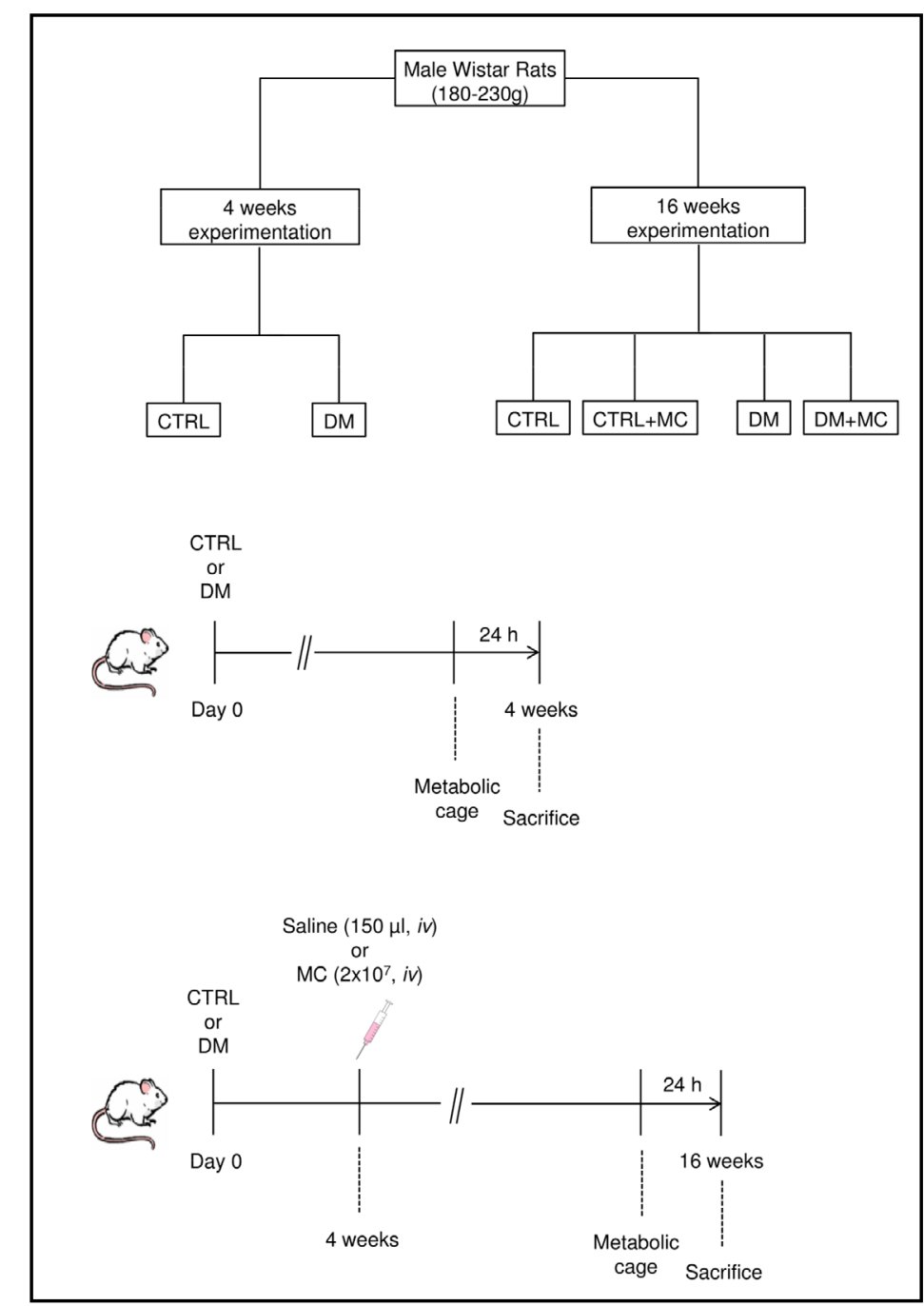

ingested over the $24 \mathrm{~h}$ was measured and urine was collected for the same period for analysis of creatinine (kinetic assay), glucose (enzymatic colorimetric assay), total protein (colorimetric assay), sodium (flame photometry), potassium (flame photometry) and chloride levels (colorimetric assay). After $24 \mathrm{~h}$ in metabolic cages, the animals were anesthetized with ketamine $(75 \mathrm{mg} / \mathrm{kg}$ b.w. $)$ and xylazine $(10 \mathrm{mg} / \mathrm{kg} \mathrm{b.w.})$ and their peritoneal cavity was exposed. Blood was collected from the inferior vena cava with a 1-ml tuberculin syringe previously rinsed with $0.1 \mathrm{M}$ EDTA. Immediately after collection, the blood was placed on ice and centrifuged at $5000 \times \mathrm{g}$ for $5 \mathrm{~min}$ at $4^{\circ} \mathrm{C}$ for plasma separation. Creatinine, urea, glucose, sodium, potassium, and chloride analyses were performed as mentioned above.

The creatinine clearance was calculated using the following equation: (urinary flow $\times$ urinary creatinine concentration) $/$ plasma creatinine concentration $=\mathrm{ml} / \mathrm{min}$. The glomerular filtration rate was determined using creatinine clearance normalized by body weight $(\mathrm{ml} / \mathrm{min}$ per $\mathrm{kg})$.

The clearance of sodium, potassium, and chloride was calculated using the following equation: (urinary flow $\times$ urinary solute concentration) $/$ plasma solute concentration $=\mathrm{ml} / \mathrm{min}$. The equation to determine the fractional excretion of each electrolyte was (electrolyte clearance/creatinine clearance) $\times 100$.

The level of proteinuria was obtained from the protein concentration in urine multiplied by the total urine volume per day.

\section{Characterization of Mononuclear Bone Marrow Cells Using Flow Cytometry}

The MC population used in the experiments was characterized by flow cytometry (BD FACSAria IIu, BD Biosciences, USA). MCs ( $5 \times 10^{5}$ cells) were incubated for 20 minutes in RT with the following anti-rat antibodies: anti-Granulocytes-FITC and anti-CD34-PE (from Santa Cruz Biotechnology, USA), anti-CD45- 
PerCP-Cy5.5 (from BD Biosciences, USA), anti-CD90-PE (from BD Pharmingen, USA), anti-CD11b/c-FITC (from Caltag Laboratories - Invitrogen). All antibody dilutions were 1:100 in PBS. After incubation, samples were fixed with a lysing/ fixing solution (BD Lysing Solution, BD Biosciences, USA) for 15 minutes and washed in PBS before analysis in a flow cytometer. Data analyses were performed using FlowJo v.7.6.3 software (Tree Star Inc., USA).

\section{Tissue preparation}

After blood collection, the animals were perfused with sterile saline containing heparin $(10 \mathrm{U} / \mathrm{ml})$ via the left cardiac ventricle. Their right kidney pediculum was clamped, the right kidney was excised, and total protein was extracted. After excision of the right kidney, the animals were perfused with paraformaldehyde $4 \%$ via the left cardiac ventricle and the left kidney was then excised and processed for histological analysis.

\section{Protein extraction and ELISA analysis}

The renal tissue was homogenized in lysis buffer (250 mM sucrose, 20 mM HEPES, 1 mM EDTA, 50 mM $\mathrm{NaF}, 1 \mathrm{mM}$ phenylmethylsulfonyl fluoride, $1 \times$ Roche protease inhibitor cocktail (Roche Diagnostic, Mannheim, Germany) using a glass Potter homogenizer with a Teflon piston (10 strokes). After homogenization, the tissue homogenate was centrifuged at $600 \times \mathrm{g}$ for $5 \mathrm{~min}$. The pellet was discarded and the supernatant was transferred to a new tube and centrifuged again at $3000 \times \mathrm{g}$ for $10 \mathrm{~min}$. The total content of TGF- $\beta 1$, IL-6, vascular endothelial growth factor (VEGF), IL-10, tumor necrosis factor (TNF)- $\alpha$, and interferon (IFN)- $\gamma$ proteins in the kidney was quantified using specific ELISA kits (Peprotech, Invitrogen).

\section{Histology}

The kidneys from the animals sacrificed 16 weeks after the start of the experiments were sectioned midfrontally into 2 pieces, immersed in Gendre's fixative solution, and embedded in paraffin. Sections were cut 4- $\mu \mathrm{m}$ thick and stained with periodic acid-Schiff reagent (PAS) to visualize the basement membrane or with a modified Picrosirius Red technique for collagen [25]. Immunohistochemical procedures on the paraffin-embedded sections included (1) a mouse monoclonal antibody against rat ED1 to detect macrophages (AbD Serotec, Raleigh, NC), (2) a mouse monoclonal antibody against rat nestin (AbD Serotec, Raleigh, NC), and (3) a rabbit polyclonal antibody against rat arginase I (Santa Cruz Biotechnology, CA, USA). ED1 and nestin antibodies were visualized using the Dako LSAB® 2 system HRP kit (Dako) using diaminobenzidine as the chromogenic substrate (Liquid DAB, Dako).

For co-localization of arginase I and ED1, paraffin sections were dewaxed, hydrated in graded ethanol, and incubated in PBS containing 5\% bovine serum albumin,0.01\% gelatin, $0.01 \%$ Tween-20, and $0.05 \%$ Triton X-100. The sections were then immersed in 5\% borohydroxide, incubated in a permeabilization PBS solution containing $0.5 \%$ Triton $\mathrm{X}-100$ and heated in $10 \mathrm{mM}$ sodium citrate ( $\mathrm{pH} 6.0$ ) to $98^{\circ} \mathrm{C}$ for $10 \mathrm{~min}$ followed by $90 \mathrm{~min}$ to cool down to room temperature to retrieve the antigens. The remaining endogenous peroxidase (catalase) activity was inactivated where appropriate by exposing the sections to $3 \% \mathrm{H}_{2} \mathrm{O}_{2}$ in methanol for $30 \mathrm{~min}$. After blocking with PBS solution containing 10\% bovine serum albumin, $0.01 \%$ gelatin, $0.05 \%$ Tween-20, and $0.1 \%$ Triton X-100 plus $20 \%$ goat serum and $20 \%$ rat serum, sections were incubated overnight in a humid chamber $\left(4^{\circ} \mathrm{C}\right)$ with a rabbit polyclonal antibody against rat arginase I. In a subsequent step, the sections were washed with PBS containing 0.25\% Tween-20 and incubated with goat anti-rabbit Alexa 546 (Invitrogen Co, Carlsbad, CA). Finally, the sections were incubated with a mouse monoclonal antibody against rat ED1 (AbD Serotec), which was visualized with a goat F(ab')2 anti-mouse IgG + IgM conjugated with fluorescein isothiocyanate (Caltag), washed, and incubated with DAPI (4',6-diamidino-2phenylindole; Santa Cruz Biotechnology) to stain the nuclei.

For all histological analysis, simultaneous negative control staining reactions were performed without the primary antibody. No positive staining was obtained in these controls.

\section{Histomorphometry}

For histomorphometry, an image analysis system composed of a digital camera (Evolution, Media Cybernetics Inc., Bethesda, MD) coupled to a light microscope (Eclipse 400, Nikon) was used. High quality images (2048×1536 pixels buffer) were captured with Pro Plus 4.5.1 software (Media Cybernetics). All the quantifications were done by one observer. 
Glomerular histological analysis

PAS-stained sections were used to capture 15-20 photomicrographs of glomerulus, chosen randomly. Glomerular area and glomerular tuff area were measured in each image using Image-Pro Plus Software version 4.5.1 for Windows (Media Cybernetics, Silver Spring, MD, USA).

Deposition of collagen fibers

Picrosirius Red staining was used to quantify the total area of collagen fibers in the glomerulus and in the tubulointerstitium area (15-20 photomicrographs each). The fields were chosen randomly and the results represent the percentage of total collagen fibers per tissue area and are expressed as means \pm standard error of the mean (SEM).

\section{Nestin $^{+}$density quantification}

To analyze the integrity of renal epithelial cells (podocytes), nestin expression was detected by immunohistochemistry. Nestin-stained sections were used to capture 20 photomicrographs from glomerulus. The results represent the percentage of nestin immunodetected in the total glomerular tuff area and are expressed as means \pm SEM.

Quantification of the glomerulus containing ED1+ cells

To observe the presence of macrophages in the renal tissue, the expression of ED1, a glycoprotein present in lysosomal membranes of tissue macrophages, was analyzed by immunohistochemistry. One hundred glomeruli from each kidney section stained with ED1 were randomly chosen and the glomeruli containing ED1 $1^{+}$cells were counted. The results represent the percentage of glomeruli that contained ED1 ${ }^{+}$ cells and are expressed as means \pm SEM.

\section{Quantification of the glomerulus containing double-stained (EDI+/arginase $\left.I^{+}\right)$cells}

Histological sections double-stained for ED1 and arginase I were examined to quantify the number of glomeruli that contained double-stained (ED1 $1^{+} /$arginase $\left.\mathrm{I}^{+}\right)$cells. ED1 is expressed in classically activated and alternatively activated tissue macrophages (M1 and M2 macrophages, respectively), and arginase I is expressed in M2 macrophages [26-28]. A total of 70-100 glomeruli from each double-stained section were observed for this analysis. The results represent the percentage of glomeruli that contained ED $1^{+} /$arginase $\mathrm{I}^{+}$cells and are expressed as means \pm SEM.

Tracing the bone marrow-derived MCs

To evaluate if MCs home to the injured kidneys, bone marrow-derived MCs were incubated with the fixable amine-reactive fluorescent tracer CellTrace ${ }^{\mathrm{TM}}$ Far Red DDAOSE (Invitrogen, Eugene, OR), according to the manufacturer's instructions and infused into CTRL and DM rats (2 rats per group) assigned only for this analysis. The animals were sacrificed $24 \mathrm{~h}$ or 6 days after infusion of MCs. Perfusion was performed with sterile saline containing heparin $(10 \mathrm{U} / \mathrm{ml})$ via the left cardiac ventricle followed by $4 \%(\mathrm{w} / \mathrm{v})$ buffered paraformaldehyde solution and then with a 1:1 mixture of paraformaldehyde and $10 \%(\mathrm{w} / \mathrm{v})$ sucrose. The kidneys were removed, cryopreserved in $30 \%(\mathrm{w} / \mathrm{v})$ sucrose in PBS, embedded in Tissue-Tek OCT compound (Tissue-Tek $®$, Sakura Finitek USA, Torrance, CA) and frozen at $-80^{\circ} \mathrm{C}$. Frozen sections $(10-\mu \mathrm{m}$ thick) were obtained, collected onto slides coated with poly-L-lysine and fixed with cold acetone. The sections were washed with PBS and incubated with 5\% (w/v) bovine serum albumin in PBS before being stained with $10 \mu \mathrm{g} / \mathrm{ml}$ TO-PRO-3 (Invitrogen, Eugene, OR). The sections were washed in PBS and coverslipped with Vectashield mounting medium (Vector Laboratories, Burlingame, CA). A Zeiss confocal microscope LSM 510 META NLO was used to visualize Far Red DDAO, with excitation at $543 \mathrm{~nm}$.

\section{Statistical analysis}

Data are expressed as means \pm SEM and the normality of the data was tested. If this condition was satisfied, the data were analyzed by one-way analysis of variance (ANOVA) followed by the Neuman-Keuls multiple comparison test or by unpaired Student's $t$ test using GraphPad Prism 4.0 software (GraphPad, San Diego, CA, USA). Statistical significance was inferred at a 2-sided value of $\mathrm{P}<0.05$. 


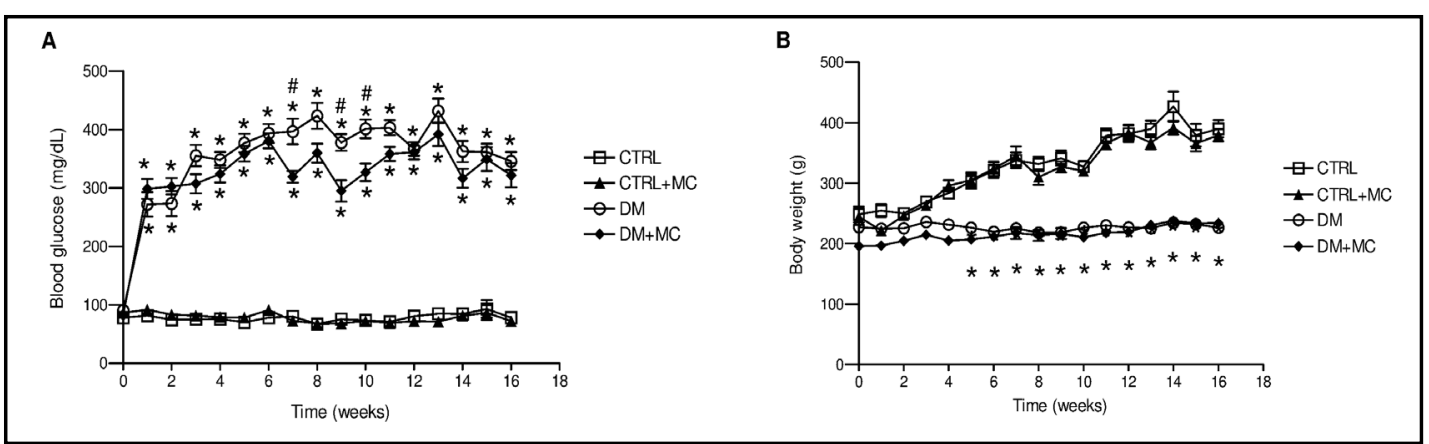

Fig. 2. Glycemic levels and body weight of the animal groups during the experiment. (A) The DM and $\mathrm{DM}+\mathrm{MC}$ groups, after fasting for $5 \mathrm{~h}$, show higher blood glucose concentrations compared with the CTRL and CTRL+MC groups (n=13); (B) The body weight of DM and DM+MC rats was lower than the CTRL and $\mathrm{CTRL}+\mathrm{MC}$ rats $(\mathrm{n}=13)$. All values are compared in each week and are presented as mean $\pm \mathrm{SEM}$. * indicates significant difference from CTRL, $\mathrm{P}<0.05$. \# DM vs. DM+MC, $\mathrm{P}<0.05$.

\section{Results}

\section{Blood glucose and body weight}

To confirm the establishment of type 1 diabetes mellitus, the blood glucose level and body weight of all rats were measured throughout the experiments. DM and DM+MC rats maintained higher blood glucose levels compared with CTRL and CTRL+MC rats after induction of diabetes (Fig. 2A). An increase in body weight in the CTRL and CTRL+MC rats during the 16 weeks after induction of diabetes was observed compared with DM and $\mathrm{DM}+\mathrm{MC}$ rats (Fig. 2B). These results show that injection of bone marrow-derived MCs did not reduce the blood glucose concentration and did not increase body weight in diabetic rats.

\section{Characterization of bone marrow-derived mononuclear cells}

MCs were characterized by flow cytometry to determine the percentage of the different cell types in the mononuclear fraction $(n=3)$. Samples presented $96.1 \pm 1.5 \%$ of hematopoietic cells (CD45') and $3.4 \pm 0.81 \%$ of non-hematopoietic cells (CD45-) (Fig. 3A). We observed that $\mathrm{CD} 45^{+}$cells in the MC fraction were constituted by $48.8 \pm 13.2 \%$ of granulocytes (CD45 $5^{+}$Granulocytes+) (Fig. 3C), 8.03 $\pm 0.39 \%$ of monocytes (CD $45^{+} / \mathrm{CD} 11 \mathrm{~b} / \mathrm{c}^{+}$) (Fig. 3B), $2.1 \pm 0.53 \%$ of hematopoietic precursors (SSC low $/ \mathrm{CD}^{+} 5^{+} / \mathrm{CD} 34^{+}$) (Fig. 3E) and $5.2 \pm 0.43 \%$ of mature lymphocytes (SSC low/CD45 $/$ CD90) and 35.9 $\pm 3.5 \%$ (SSC low/CD $45^{+} / \mathrm{CD}^{-} 0^{+}$) of immature hematopoietic progenitor cells (Fig. 3F). In CD45 subpopulation, cells presenting mesenchymal stem cell markers were about $0.23 \pm 0.058 \%$ (Fig. 3D). All presented percentages above are related to the total acquired events analyzed (approximately $10^{5}$ events recorded).

\section{Effects of the infusion of bone marrow-derived MCs on renal function}

Renal function was assessed in a group of animals 4 weeks after induction of diabetes and this experiment was performed to analyze the renal function of the diabetic animals at the time of injection of bone marrow-derived MCs. The other animals were subjected to the same procedure 16 weeks after induction of diabetes.

Four weeks after induction of diabetes, the DM rats showed an increase in urinary flow, plasma creatinine, glomerular filtration rate, plasma urea and glucose, sodium, and chloride fractional excretion compared with CTRL rats. No changes in potassium fractional excretion were observed (Table 1).

Sixteen weeks after induction of diabetes, DM rats showed an increase in urinary flow, glomerular filtration rate, proteinuria, and glucose, sodium, chloride, and potassium fractional excretion compared with CTRL rats. Plasma creatinine was not significantly different between all groups. DM+MC rats did not show any improvements in glucose, sodium, chloride, and potassium fractional excretion and proteinuria compared with DM 


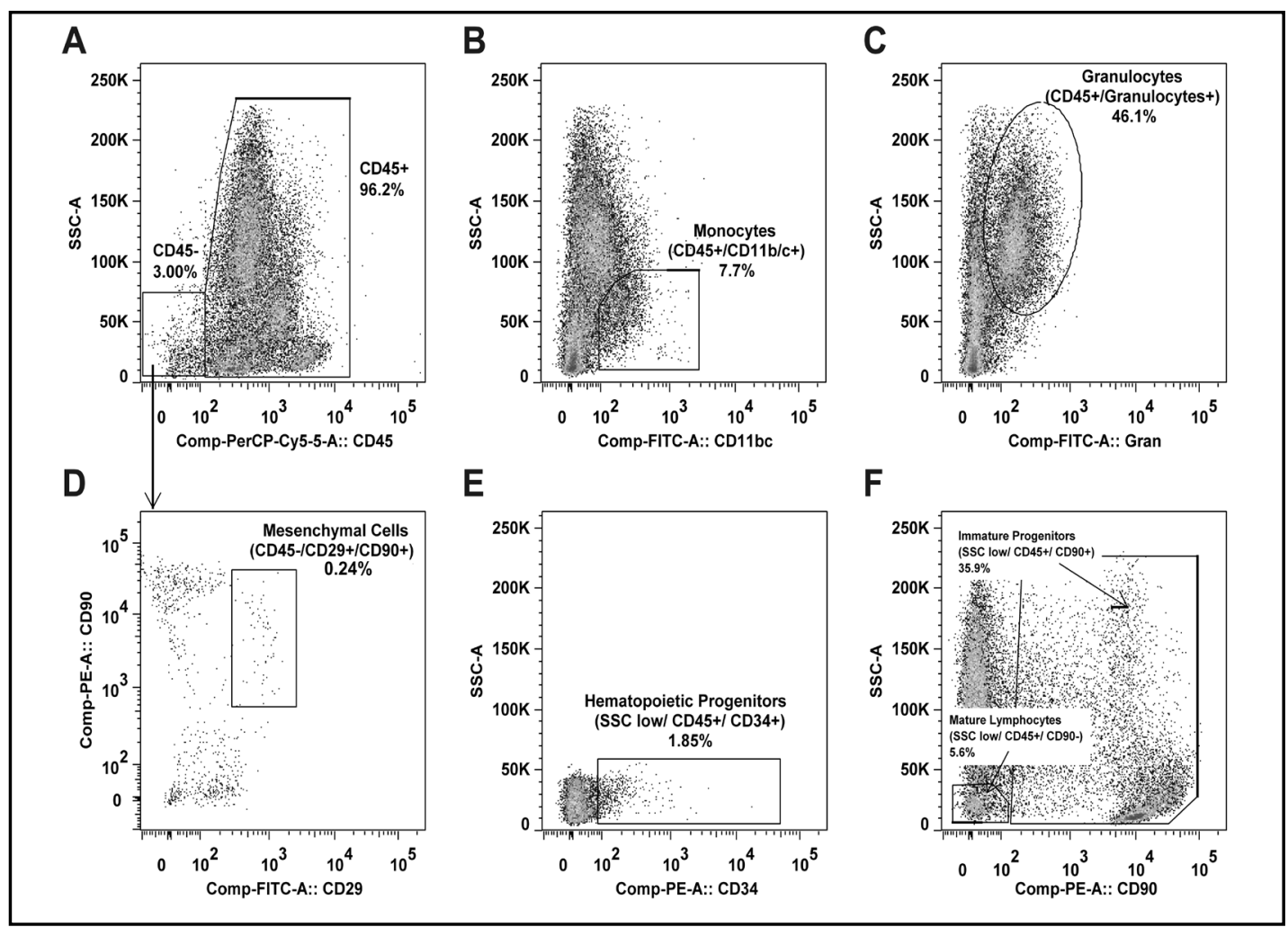

Fig. 3. Representative dot plots analysis of rat bone marrow MC immunophenotyping. (A) Percentage of hematopoietic (CD45+) and non-hematopoietic (CD45-) cells. After identifying those subpopulations, MC were constituted by monocytes (B), granulocytes (C), mesenchymal stem cells (D), hematopoietic progenitors $(\mathrm{E})$, immature progenitors and mature progenitors $(\mathrm{F})$.

Table 1. Urinary flow, plasma creatinine, glomerular filtration rate (GFR), plasma urea, proteinuria, and fractional excretion (FE) of $\mathrm{Na}+, \mathrm{Cl}-$, and $\mathrm{K}+$ in CTRL and DM groups 4 weeks after induction of diabetes. All values are represented as mean \pm SEM $(n=5) . *$ indicates significant difference from CTRL, $\left({ }^{*}\right) \mathrm{P}<0.05$, ( $\left.{ }^{* * *}\right) \mathrm{P}<0.001$

\begin{tabular}{llc}
\hline & \multicolumn{2}{c}{4 weeks } \\
& \multicolumn{1}{c}{ CTRL } & DM \\
\hline Urinary flow (ml/day) & $12.5 \pm 2.03$ & $53.9 \pm 14.5^{*}$ \\
Plasma creatinine (mg/dL) & $0.460 \pm 0.0245$ & $0.383 \pm 0.0167^{*}$ \\
GFR (ml/min/kg) & $5.31 \pm 0.599$ & $10.2 \pm 1.38^{*}$ \\
Plasma urea (md/dL) & $27.2 \pm 4.21$ & $54.5 \pm 6.83^{*}$ \\
Proteinuria (mg/day) & $10.0 \pm 1.84$ & $20.4 \pm 4.85$ \\
Glucose FE (\%) & $0.135 \pm 0.0523$ & $49.3 \pm 8.87^{* * *}$ \\
Na+ FE (\%) & $0.254 \pm 0.0475$ & $0.448 \pm 0.0513^{*}$ \\
Cl- FE (\%) & $0.654 \pm 0.0761$ & $1.04 \pm 0.126^{*}$ \\
$\mathrm{~K}^{+}$FE (\%) & $36.1 \pm 4.45$ & $35.6 \pm 3.78$ \\
\hline
\end{tabular}

rats. However, $\mathrm{DM}+\mathrm{MC}$ rats showed a reduction of urinary flow and plasma urea compared with DM rats, although the values were higher than for the CTRL rats. A reduction of the glomerular filtration rate to CTRL group values was observed in DM+MC rats (Table 2). 


\begin{tabular}{lcccc}
\hline & & \multicolumn{2}{c}{16 weeks } & \\
& CTRL & CTRL+MC & DM & DM+MC \\
\hline Urinary flow (ml/day) & $7.55 \pm 0.717$ & $12.2 \pm 2.11$ & $67.4 \pm 8.85^{* * *}$ & $49.0 \pm 8.12^{* * * \#}$ \\
Plasma creatinine (mg/dL) & $0.500 \pm 0.0169$ & $0.471 \pm 0.0286$ & $0.433 \pm 0.0188$ & $0.423 \pm 0.0201$ \\
GFR (ml/min/kg) & $3.73 \pm 0.236$ & $4.26 \pm 0.274$ & $9.88 \pm 2.93^{*}$ & $5.82 \pm 0.329 \#$ \\
Plasma urea (mg/dL) & $34.9 \pm 2.11$ & $40.1 \pm 2.15$ & $80.6 \pm 4.59^{* * *}$ & $66.3 \pm 2.38^{* * * \# \#}$ \\
Proteinuria (mg/day) & $10.3 \pm 0.862$ & $13.6 \pm 1.87$ & $27.6 \pm 2.71^{* * *}$ & $22.2 \pm 2.33^{* * *}$ \\
Glucose FE (\%) & $0.0710 \pm 0.0142$ & $0.149 \pm 0.0571$ & $90.3 \pm 31.2^{* *}$ & $63.5 \pm 15.3^{*}$ \\
Na+ FE (\%) & $0.226 \pm 0.0415$ & $0.272 \pm 0.0467$ & $0.622 \pm 0.128^{* *}$ & $0.637 \pm 0.0896^{* *}$ \\
Cl- FE (\%) & $0.382 \pm 0.0597$ & $0.420 \pm 0.0720$ & $1.43 \pm 0.384^{* *}$ & $1.10 \pm 0.185^{*}$ \\
K+ FE (\%) & $12.4 \pm 2.62$ & $14.0 \pm 2.06$ & $37.2 \pm 5.95^{* * *}$ & $40.3 \pm 6.67^{* * *}$ \\
\hline
\end{tabular}

Table 2. Urinary flow, plasma creatinine, glomerular filtration rate (GFR), plasma urea, proteinuria, and fractional excretion (FE) of $\mathrm{Na}^{+}, \mathrm{Cl}^{-}$, and $\mathrm{K}^{+}$in CTRL, CTRL+MC, DM and DM+MC groups 16 weeks after induction of diabetes. All values are represented as mean \pm SEM $(n=10)$. ). * indicates significant difference from CTRL, $\left.\left({ }^{*}\right) \mathrm{P}<0.05,{ }^{* *}\right) \mathrm{P}<0.01,\left({ }^{* * *}\right) \mathrm{P}<0.001$. ${ }^{*} \mathrm{DM}$ vs. $\mathrm{DM}+\mathrm{MC}$, (\#) $\mathrm{P}<0.05$, (\#\#) $\mathrm{P}<0.01$

Localization of bone marrow-derived mononuclear cells in the kidneys

One day after injection, labeled MCs could be localized in the renal tubulointerstitium and in the glomerulus of DM+MC animals. However, 6 days after injection, labeled MCs were difficult to be observed in histological sections of kidneys. The rare positive cells were found surrounding the glomerulus but not in the renal tubulointerstitium area (Fig. 4). In the kidneys of CTRL+MC animals, labeled MCs were rare (data not shown).

\section{Renal morphology after injection of bone marrow-derived MCs}

Rat renal morphology was analyzed 16 weeks after induction of diabetes. Kidneys from the DM group showed an increase in glomerular tuff area $(65.18 \pm 1.598 \%)$ compared with the CTRL group (54.56 $\pm 1.665 \%$ ) (Fig. 5) and showed cytoplasmic vacuolations in cortical tubular cells (data not shown). The DM+MC group showed a reduction of the glomerular tuff area $(59.01 \pm 2.529 \%)$ compared with the DM group, reaching control values. However, tubular cytoplasmic vacuolations were still observed in DM+MC rats compared with DM rats. Total collagen fiber measurements within the glomeruli and in the tubulointerstitium were not different among the groups (Fig. 6). Nestin expression was lower in DM (13.93 $\pm 2.527 \%)$ and $\mathrm{DM}+\mathrm{MC}(10.83 \pm 0.4646 \%)$ glomeruli compared with the CTRL group $(22.63 \pm 3.996 \%)$ (Fig. 7).

\section{IL-6, VEGF, and TGF- $\beta 1$ expression in the kidneys}

Four weeks after induction of diabetes, expression of IL-6, VEGF, and TGF- $\beta 1$ proteins in whole kidney was higher in the DM group than in the CTRL group $(2.2 \pm 0.39$-fold, $2.1 \pm 0.40$ fold, and 1.6 \pm 0.14 -fold, respectively) (Fig. 8). Sixteen weeks after induction of diabetes, expression of IL- 6 and VEGF renal proteins was not different among the experimental groups. However, the expression of TGF- $\beta 1$ renal protein was $1.3 \pm 0.09$-fold in the DM group compared with the CTRL group. The expression of TGF- $\beta 1$ in the DM+MC group was similar to the values found for the CTRL group (0.9 \pm 0.17 -fold) (Fig. 8). 
Fig. 4. Representative photomicrograph of localization of bone marrow-derived MCs in the diabetic kidney. MCs were labeled with CellTrace $^{\mathrm{TM}}$ Far Red DDAOSE and injected in DM+MC animals 4 weeks after induction of diabetes. One or 6 days after injection, MCs were localized by confocal microscopy. White arrows indicate the labeled MCs, shown in red. Cell nuclei were labeled with TO-PRO-3 and are shown in blue. Bars $=50 \mu \mathrm{m}$.
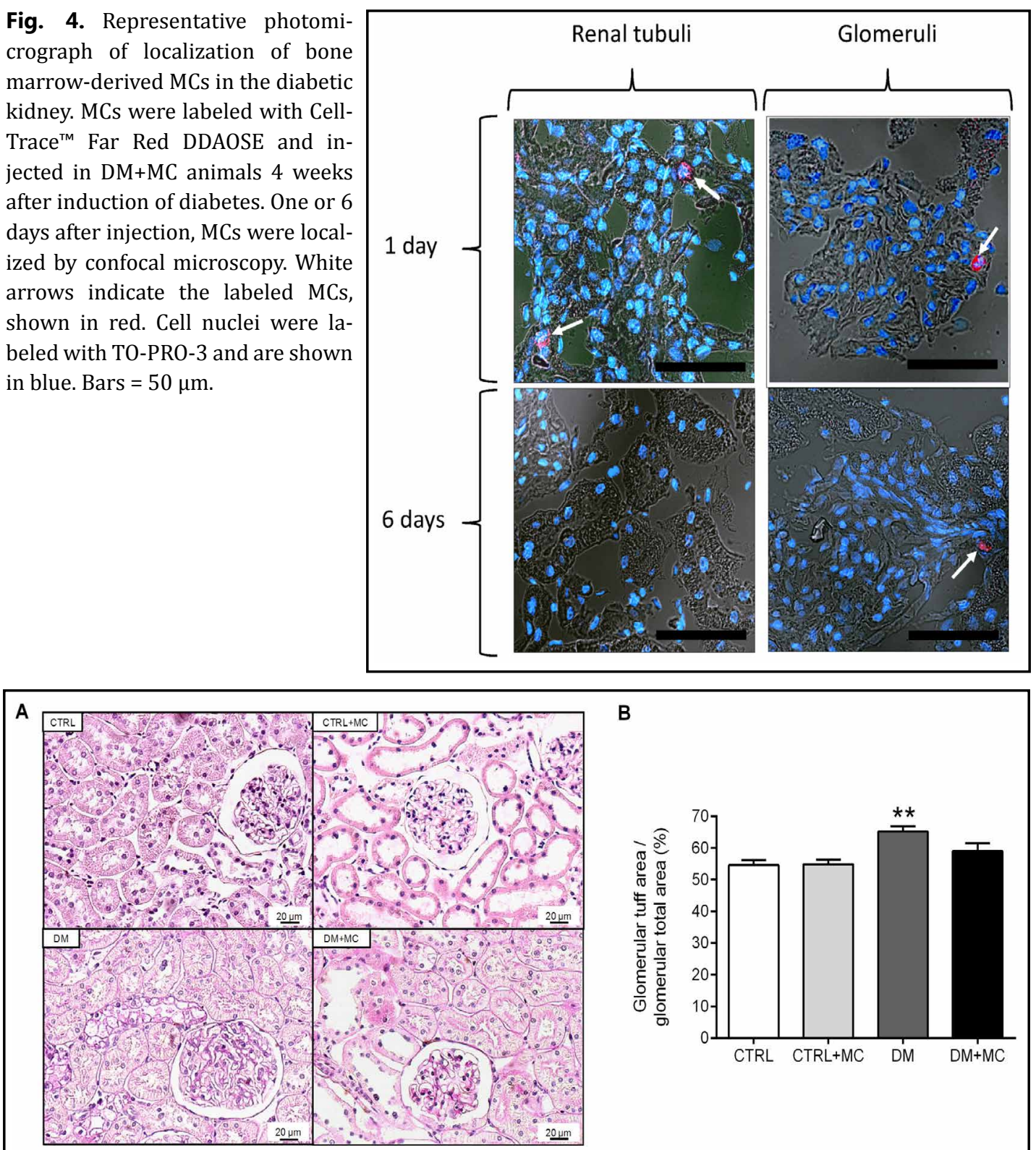

B

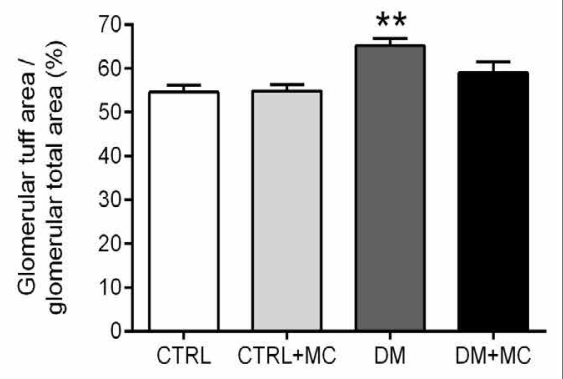

Fig. 5. Measurement of glomerular structure. (A) Representative photomicrograph of kidney sections stained with PAS emphasizing the glomeruli of CTRL, CTRL+MC, DM, and DM+MC animals 16 weeks after induction of diabetes. (B) Graphic representation of the relation between glomerular tuff area and glomerular total area for the CTRL, CTRL+MC, DM, and DM+MC groups $(n=6)$. All values are presented as mean \pm SEM. ** indicates significant difference from CTRL.

\section{Macrophage infiltration in diabetic kidneys}

The percentage of glomeruli containing ED1 ${ }^{+}$cells was not different in the CTRL, CTRL+MC, and DM groups. However, the DM+MC group showed an aproximately 2.5 -fold and 1.9-fold increase in ED1 ${ }^{+}$glomeruli compared with CTRL and DM groups, respectively (Fig. 9). Macrophage number per glomerular section was aproximately 3.3-fold and 2.1-fold higher in DM+MC group if compared to CTRL and DM groups, respectively.

Figure 10A shows that 1 of the 5 glomeruli represented in CTRL photomicrography, 1 of the 4 in $\mathrm{CTRL}+\mathrm{MC}, 1$ of the 4 in $\mathrm{DM}$ and 3 of the 5 in DM+MC are ED1+/arginaseI+ positive. 
Fig. 6. Deposition of renal collagen fibers 16 weeks after induction of diabetes. (A) Representative photomicrograph of glomeruli stained with Picrosirius Red from CTRL, CTRL+MC, DM, and $\mathrm{DM}+\mathrm{MC}$ rats. (B) Graphic representation of the relation between the area of glomerular collagen fibers and glomerular tuff area for the

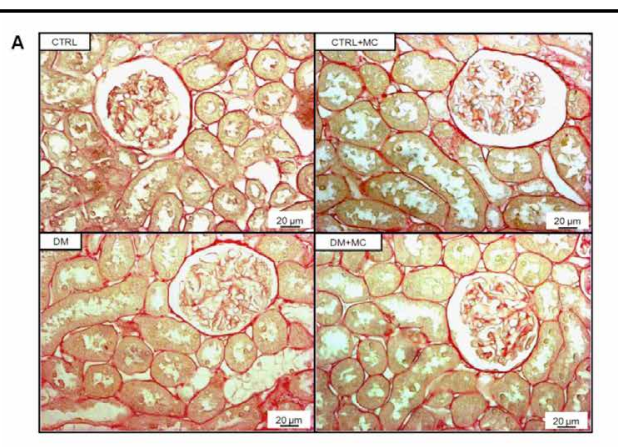

B

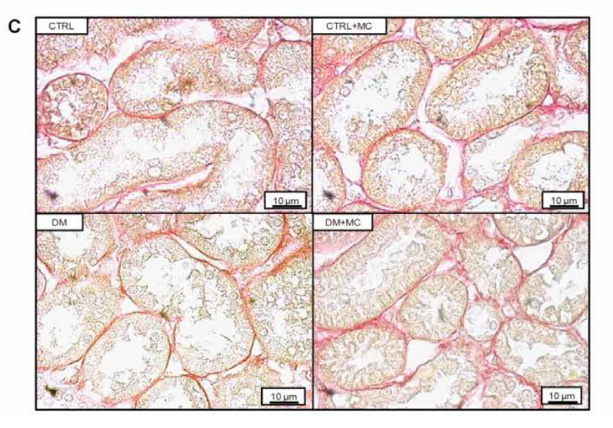

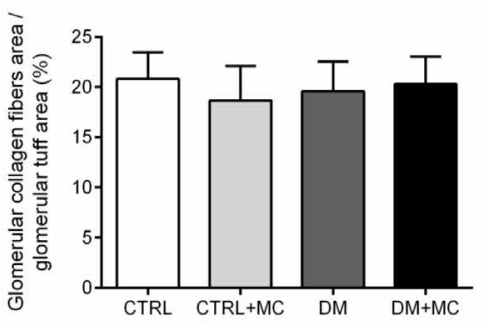

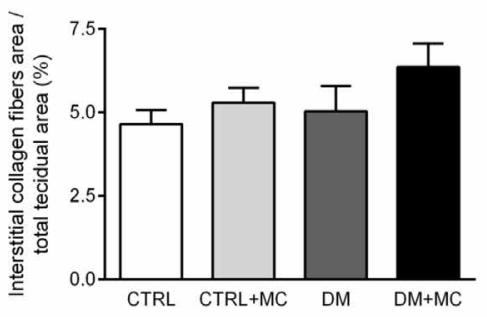

CTRL, CTRL+MC, DM, and DM+MC groups. (C) Representative photomicrograph the tubulointerstitium area stained with Picrosirius Red from CTRL, CTRL+MC, DM, and DM+MC rats. (D) Graphic representation of the relation between the area of tubulointerstitial collagen fibers and total tissue area for the CTRL, CTRL+MC, $\mathrm{DM}$, and DM+MC groups ( $\mathrm{n}=6)$. All values are presented as mean $\pm \mathrm{SEM}$.

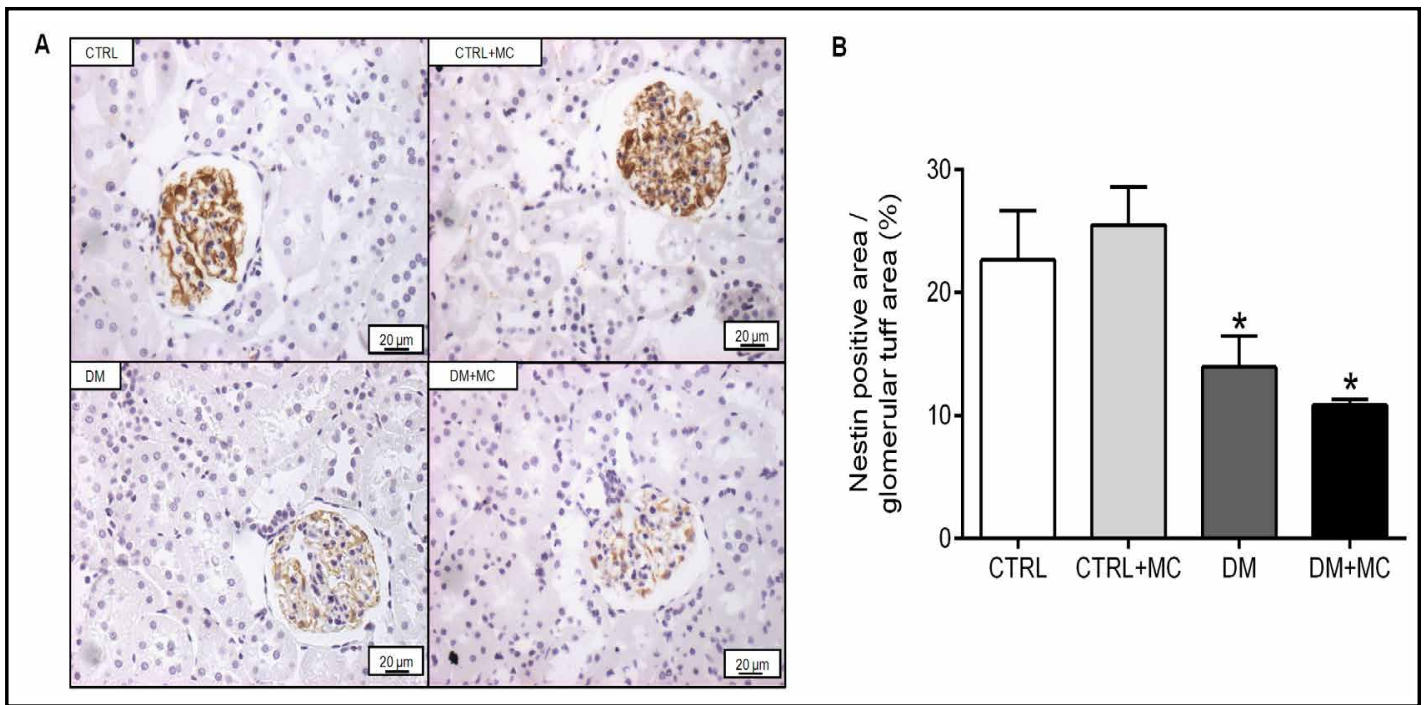

Fig. 7. Glomerular nestin positive area. (A) Representative photomicrograph of nestin staining of kidney sections from CTRL, CTRL+MC, DM, and DM+MC groups 16 weeks after induction of diabetes. (B) Graphic representation of the relation between glomerular nestin positive area and glomerular tuff area for the CTRL, CTRL+MC, DM, and DM+MC groups $(n=6)$. All values are presented as mean $\pm S E M$. * indicates significant difference from CTRL, $\mathrm{P}<0.05$.

The percentage of glomeruli containing cells double-stained for ED1 and arginase I was not different in the CTRL, CTRL+MC, and DM groups, but it was approximately 3.4-fold and 2.9fold higher in the DM+MC group compared with CTRL and DM groups, respectively (Fig. 10). 
A

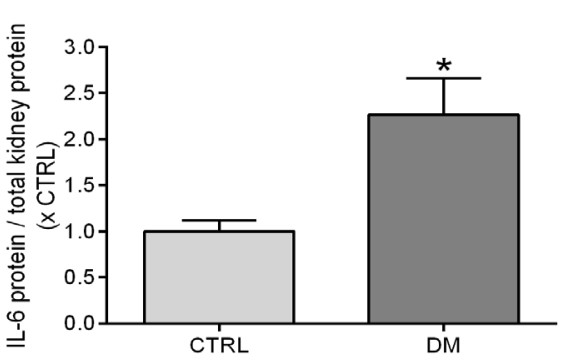

C

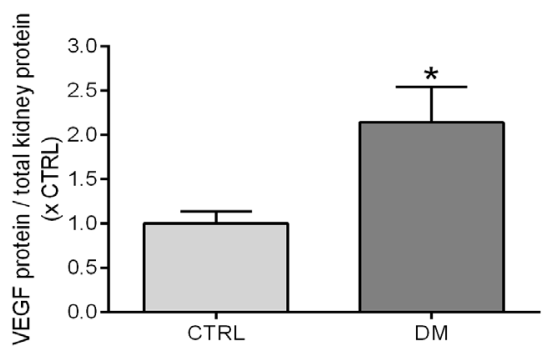

E

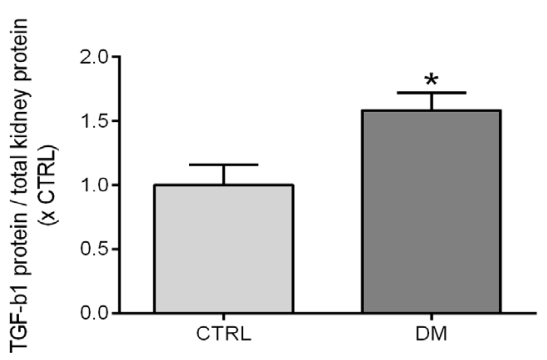

B

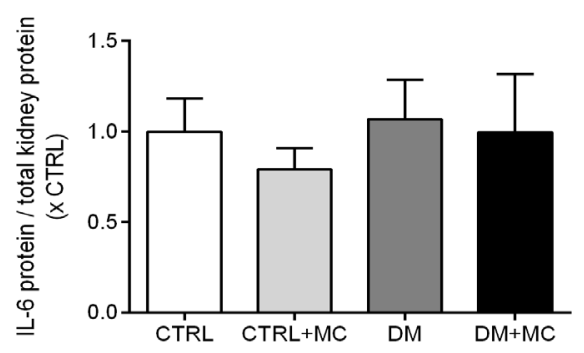

D

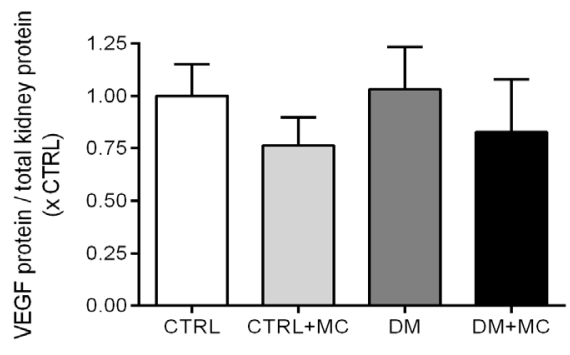

$\mathbf{F}$

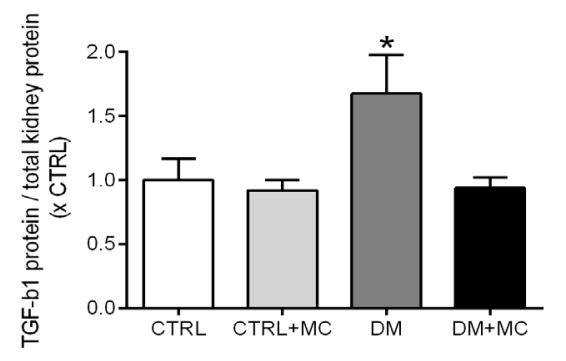

Fig. 8. ELISA analysis of renal IL-6, VEGF and TGF- $\beta 1$ expression. All graphics present the relation between renal cytokine protein levels and total kidney protein. (A) Renal IL-6 expression 4 weeks after induction of diabetes ( $n=5)$. (B) Renal IL-6 expression 16 weeks after induction of diabetes ( $n=8)$. (C) Renal VEGF expression 4 weeks after induction of diabetes ( $n=5)$. (D) Renal VEGF expression 16 weeks after induction of diabetes (n=8). (E) Renal TGF- $\beta 1$ expression 4 weeks after induction of diabetes $(n=5)$. (F) Renal TGF- $\beta 1$ expression 16 weeks after induction of diabetes $(\mathrm{n}=8)$. All values are presented as mean \pm SEM. * indicates significant difference from CTRL, $\mathrm{P}<0.05$.

Expression of IFN- $\gamma$, TNF- $\alpha$ and IL-10 in diabetic kidneys after administration of MCs

The renal protein expression of IFN- $\gamma$, TNF- $\alpha$ and IL-10 were evaluated 16 weeks after induction of diabetes. The renal expression of IFN $-\gamma$ and TNF- $\alpha$ proteins (cytokines related to M1 macrophage activation) was not different among all the groups. However, the renal expression of IL-10 protein (secreted by M2 macrophages) was $0.49 \pm 0.098$ fold lower in DM group when compared to CTRL group (Fig. 11).

\section{Discussion}

In the present work, 4 and 16 weeks after administration of streptozotocin, hyperglycemic animals developed hyperfiltration. In addition, an increase in the glomerular tuff area was observed at 16 weeks in diabetic animals. These findings are in accordance with previous 


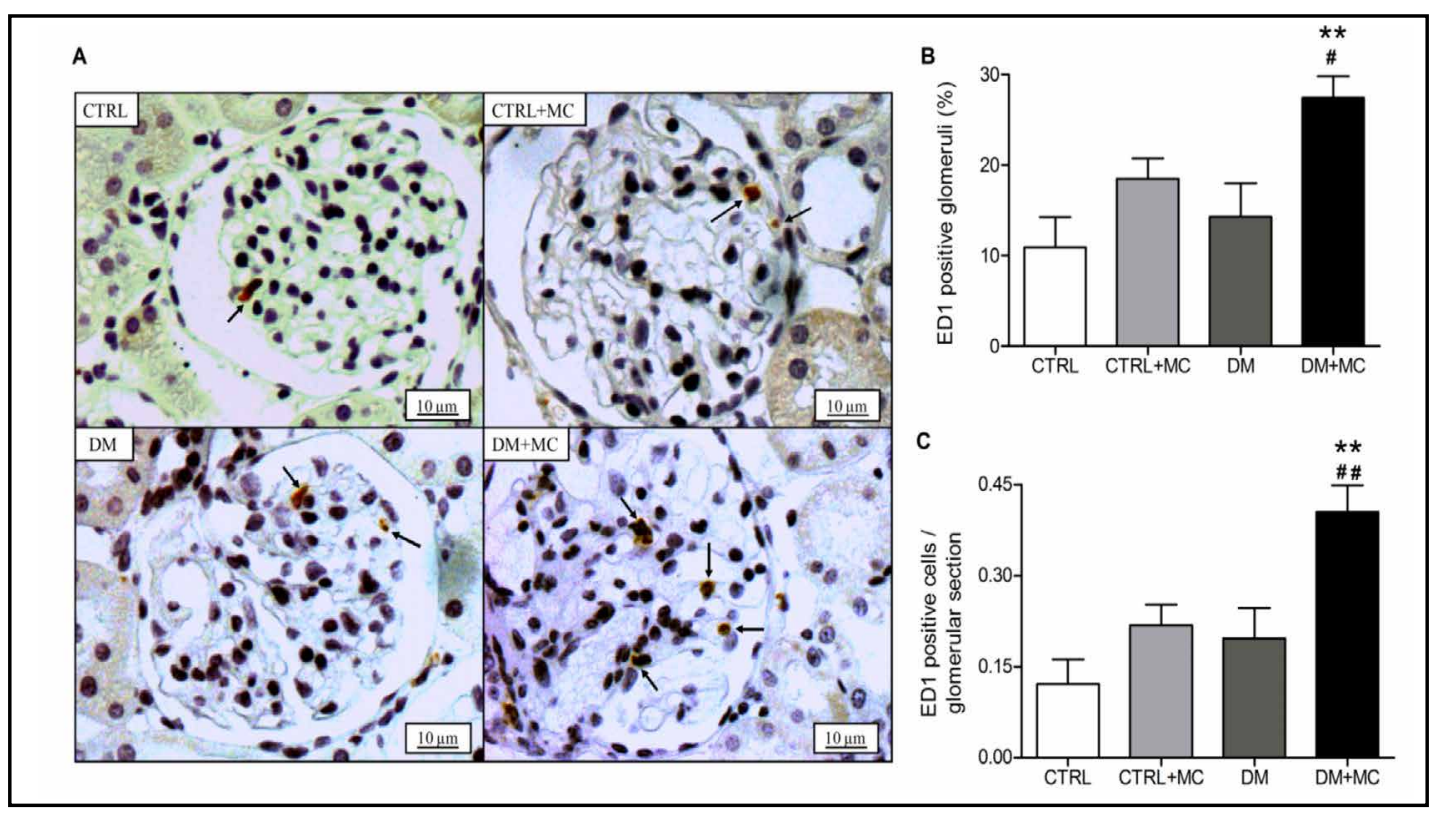

Fig. 9. Glomerular ED1 positive cells. (A) Representative photomicrograph of ED1 staining of kidney sections emphasizing glomeruli from CTRL, CTRL+MC, DM, and DM+MC rats 16 weeks after induction of diabetes. Black arrows indicate the ED1 positive cells, shown in brown. (B) Graphic representation of the percentage of glomeruli containing at least one ED1 positive cell in the CTRL, CTRL+MC, DM, and DM+MC groups ( $n=6)$. (C) Graphic representation of ED1 positive cells per glomerular section in the CTRL, CTRL+MC, DM, and $\mathrm{DM}+\mathrm{MC}$ groups $(\mathrm{n}=6)$. All values are presented as mean $\pm S E M . * *$ indicates significant difference from $C T R L$, $\mathrm{P}<0.01$. \# DM vs. DM+MC, $\mathrm{P}<0.05$. \#\# DM vs. DM+MC, $\mathrm{P}<0.01$.

works that showed an increase in glomerular filtration rate in type 1 diabetic rats at 4 weeks [29-31] and 16 weeks [3] after induction of diabetes, in both cases corresponding to an early diabetic nephropathy stage $[2,7,12]$.

Diabetic animals received a single dose of bone marrow-derived MCs constituted of a heterogeneous population of precursor cells, leucocytes, mesenchymal cells and hematopoietic cells when glomerular dysfunction was already established (4 weeks after streptozotocin administration). These animals showed a reversion of hyperfiltration that lasted for the period of the present study (12 weeks after cellular therapy) accompanied by a reduction in the glomerular tuff area despite the persistence of hyperglycemia. Nestin density was reduced in diabetic animals and was not improved in the diabetic animals that received a dose of MCs. This result suggests that an improvement in glomerular function is not related to podocyte recovery (Fig. 7).

It was previously reported that in mouse models of type 2 [32] and type 1 [33] diabetes mellitus, human bone marrow-derived mesenchymal cells were able to prevent renal injuries and pancreatic islet degenaration [32]. In both cases, because of the normalization of blood glucose levels as a result of regeneration of pancreatic islets, it is not possible to know whether mesenchymal cells were directly involved in glomerular regeneration or if this regeneration was secondary to the reduction of glycemia to euglycemic levels. On the other hand, in a nonimmunological C57BL/6 mice model of diabetes, developed with a single high dose of streptozotocin, administration of bone marrow-derived mesenchymal cells was able to prevent renal failure despite the persistence of hyperglycemia [34].

Our results show that glomerular function and morphological recoveries were not a consequence of glycemic control, suggesting that these effects were due solely to the administration of bone marrow-derived MCs. We observed that bone marrow-derived MC therapy in healthy animals had no effect on glomerular function or morphology, and is a safe therapeutic approach. Hyperglycemia was not reduced in our model compared with previous 


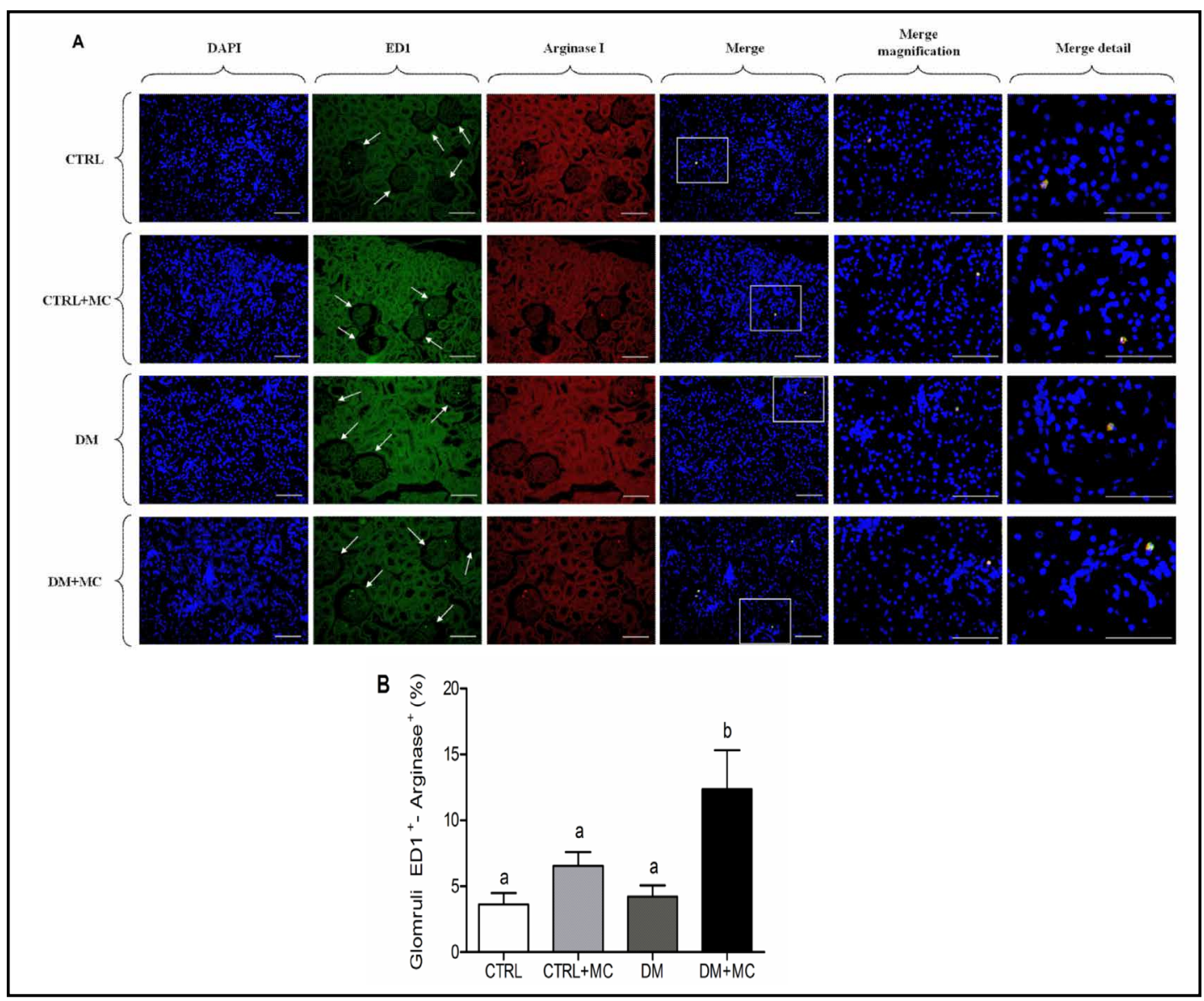

Fig. 10. Immunofluorescence staining showing ED1 and arginase I double-positive cells in rat glomeruli. (A) Representative photomicrographs of kidney sections from the CTRL, CTRL+MC, DM, and DM+MC groups 16 weeks after induction of diabetes. White arrows indicate the glomeruli evaluated in each photomicrograph. The regions outlined by the white boxes are magnified and DAPI, ED1 and Arginase I co-localization are shown. Photomicrographs from merge amplification columns and merge detail columns were obtained with $20 \mathrm{x}$ and $40 \mathrm{x}$ objective lenses, respectively. Bars $=50 \mu \mathrm{m}$. (B) Graphic representation of the percentage of glomeruli containing at least one ED1 and arginase I double-positive cell in the CTRL, CTRL+MC, DM, and $\mathrm{DM}+\mathrm{MC}$ groups $(\mathrm{n}=6)$. All values are presented as mean $\pm \mathrm{SEM}$. * indicates significant difference from CTRL, $\mathrm{P}<0.05$. \# DM vs. DM+MC, $\mathrm{P}<0.05$.

studies, probably due to: (1) the difference between animal species; (2) the protocol used to induce disruption of pancreatic beta cells; (3) the therapeutic cell type used.

In addition to glomerular alterations in diabetic nephropathy, a progressive loss of tubular function during the course of the disease has already been described, leading to interstitial fibroses in its advanced stages [35-37]. Our results show that diabetic animals presented tubular dysfunction in handling glucose and electrolytes throughout the analysis period but despite the improvement in glomerular function of diabetic animals after injection of bone marrow-derived MCs, no improvements were observed in the tubular function of these animals (Tables 1 and 2). Thus, we can infer that bone marrow-derived MC therapy 4 weeks after induction of diabetes mellitus was not able to prevent the development of alterations in tubular function in diabetic rats or restore the disrupted tubular function.

Although alterations in tubular function can be accompanied by interstitial fibrosis in the advanced stages of diabetic nephropathy, no differences in collagen deposition in 
Fig. 11. ELISA analysis of renal TNF- $\alpha, \mathrm{IFN}-\gamma$ and IL-10 expression after MC treatment in diabetic rats. All graphics present the relationship between renal cytokine protein levels and total kidney protein. (A) Renal TNF- $\alpha$ expression in the DM and DM+MC groups 16 weeks after induction of diabetes $(n=11)$. (B) Renal IFN- $\gamma$ expression in the DM and DM+MC groups 16 weeks after induction of diabetes $(n=11)$. (C) Renal IL-10 expression in the DM and DM+MC groups 16 weeks after induction of diabetes $(n=10)$. All values are presented as mean \pm SEM. * indicates significant difference from CTRL, $\mathrm{P}<0.05$.

the tubular interstitial area were observed among experimental groups after 16 weeks of hyperglycemia, suggesting that the animals were at the early phase of diabetic nephropathy.

TGF- $\beta 1$ is considered to be the main factor involved in the development and progression of diabetic nephropathy [15, 38-40]. In the present diabetic nephropathy model, we were able to observe a reduction in TGF- $\beta 1$ renal expression after treatment with bone marrow-derived MCs, along with a reduction in the glomerular filtration rate and glomerular tuff area to CTRL animal levels. The same observation was made in spontaneous hypertensive rats subjected to diabetes where the inhibition of TGF- $\beta 1$ expression by tranilast, an antiallergic drug that inhibits the release of cytokines from macrophages
A

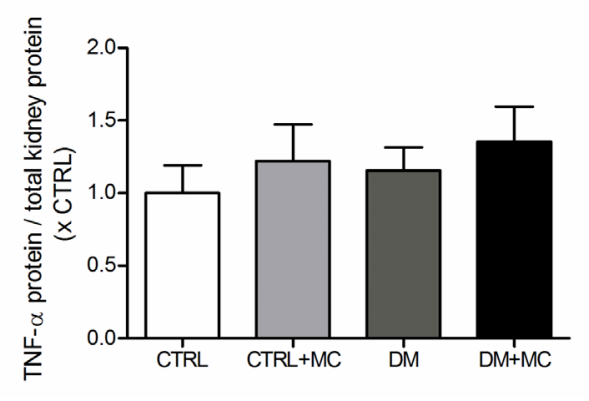

B

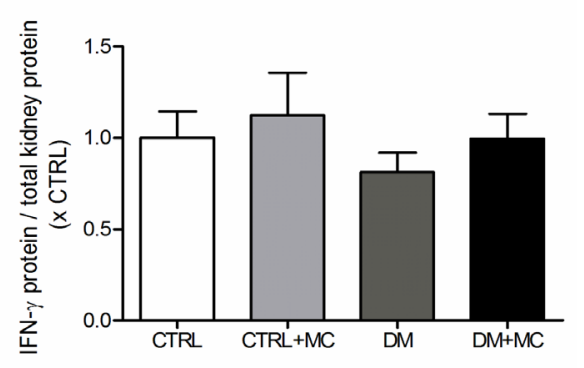

C

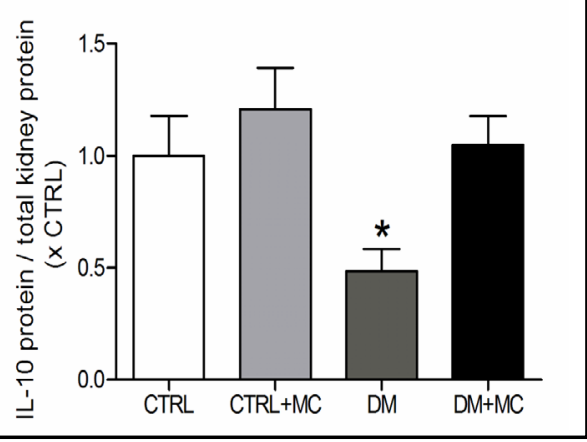
and chemical mediators from mast cells [41], led to a reduction in glomerular hyperfiltration and glomerular tuff area expansion despite persistent hyperglycemia [42].

In addition to TGF- $\beta 1$, other factors such as VEGF $[2,40,43,44]$ and IL- $6[2,45,46]$ have also been reported to be involved in the development of diabetic nephropathy. Our results suggest a role for VEGF and IL- 6 in the establishment of the disease but not in its progression because their levels were increased in animals after 4 weeks after induction of diabetes but not after 16 weeks (Fig. 8).

Diabetic nephropathy has recently been considered to be an immunological chronic disease and one of its main features is the glomerular accumulation of macrophages [46-53]. In mice injected with streptozotocin, macrophage infiltration was correlated to an increase in plasma creatinine level, albuminuria, glomerular hypertrophy, glomerular hypercellularity, and collagen IV deposition. Glomerular macrophages are prevalent in early but not advanced diabetic nephropathy and they can act early on mesangial cells to promote collagen fibers production [54]. In renal interstitium, macrophages are correlated with tubular atrophy, tubular dilatation, apoptosis, and an increase in collagen IV deposition [11, 55]. These macrophages have been described as M1 classically activated macrophages, responsible for the release of pro-inflammatory cytokines and for stimulating renal oxidative stress through the release of iNOS, leading to renal damage [55-58]. However, some investigators show that macrophage accumulation in diabetic kidney may vary according to the severity of the 
disease $[58,59]$. M1 macrophages are known for increased expression and secretion of proinflammatory cytokines such as IL-6, TNF- $\alpha$, and IFN- $\gamma$. Our results show that there are no alterations in TNF- $\alpha$ and IFN- $\gamma$ expression in the kidneys of rats comparing all groups 16 weeks after the beginning of the experiments.

M1 and M2 (alternatively activated) macrophage populations can be distinguished from each other through their cytokine expression and secretion pattern. Different subsets of M2 and M2-like macrophages have been described and are distinguished from each other by their protein synthesis and cytokine secretion profile, as reviewed elsewhere [57,60-62]. One of the main cytokines secreted in high amounts by M2 macrophages is IL-10 [63, 64], an immunoregulatory cytokine that had been associated to the termination of inflammation processes [65]. One of the main proteins expressed in M2 and M2-like macrophages is arginase I, an enzyme that converts arginine to urea and ornithine. It is important to keep in mind that arginine can also be converted to citrulline and nitric oxide (NO) by nitric oxide synthase (NOS) as a competitive pathway to the arginase pathway. In fact, NO or ornithine production are proposed to be the clearest way to distinguish opposing macrophage activities, in which M1 macrophages refer to NO production and M2 macrophages refer to ornithine production [66]. It should be taken into account that NOS and arginase levels reflect an indirect measure of NO or ornithine, the functional products of macrophages.

Arginase I positive macrophages were previously shown to be involved in wound healing and tissue repair $[26-28,67]$ and could be a possible therapeutic approach to many inflammatory diseases [58]. The production of IL-10 and arginase I by M2-like macrophages has been shown to contribute to the suppression of fibrosis $[68,69]$. In the present work we observed an increase in ED1 $1^{+}$macrophage infiltration at the glomeruli of diabetic animals that received injection of bone marrow-derived MCs but not in diabetic animals that received injection of vehicle (Fig. 9). After immunohistochemistry analysis we showed that an ED1 $1^{+}$arginase $\mathrm{I}^{+}$macrophage population was increased in glomeruli of MC-treated animals compared with the DM group (Fig. 10).

A reduction in IL-10 expression is observed in the DM group compared with control animals and it is normalized in DM+MC group (Fig. 11). A direct relation between the increase in $\mathrm{ED}^{+} /$arginase $\mathrm{I}^{+}$macrophage infiltration and IL-10 expression levels in DM+MC group cannot be assumed because other types of cells have been described as capable of producing and secreting IL-10 after stimulation, like isolated mesangial cells [70] and renal tubular cells [71]. Therefore, we can only infer that the MCs administration in the diabetic rats can increase both glomerular infiltration of a subset of macrophage that is arginase I positive and IL-10 renal expression when compared to diabetic animals without MCs administration. Further experiments are necessary to properly identify the source of the increased IL-10 renal expression observed in this experimental model.

It has already been shown that mesenchymal bone marrow cells are able to switch the phenotype of macrophages from the classically activated (M1) phenotype to the M2 phenotype in a rat model of spinal cord injury [72] and in a NOD/SCID gamma null mouse model of acute myocardial infarction [73]. M2 macrophage activation and its actions are still poorly understood and more work is needed to elucidate these questions.

Our hypothesis is that bone marrow-derived MCs might be used in the treatment of early glomerular alterations in rats submitted to diabetic nephropathy. After MC administration, and compared to DM group, the combination of an increase in arginase I positive macrophages, an increase in IL-10 expression and a decrease in renal release of TGF- $\beta$ could allow complete restoration of normal glomerular structure and function. Additional studies are warranted to further investigate the mechanisms of action of MCs in this model.

In summary, our work shows that bone marrow-derived MCs given endovenously to diabetic rats contribute to improvement in glomerular function and morphology in a rat model of type 1 diabetes mellitus, probably through a decrease in the renal content of TGF- $\beta$ together with an arginase I positive macrophage accumulation in the glomeruli. 
Castiglione et al.: Bone Marrow-Derived Mononuclear Cells and Diabetes

\section{Acknowledgements}

This study was supported by the Brazilian Council for Scientific and Technological Development (CNPq), Rio de Janeiro State Research Supporting Foundation (FAPERJ) and Coordination for the Improvement of Higher Education Personnel (CAPES).

\section{References}

1 Alberti KG, Zimmet PZ: Definition, diagnosis and classification of diabetes mellitus and its complications. Part 1: diagnosis and classification of diabetes mellitus provisional report of a WHO consultation. Diabet Med 1998;15:539-553.

2 Schrijvers BF, de Vriese AS, Flyvbjerg A: From hyperglycemia to diabetic kidney disease: the role of metabolic, hemodynamic, intracellular factors and growth factors/cytokines. Endocr Rev 2004;25:9711010.

-3 Cruzado JM, Lloberas N, Torras J, Riera M, Fillat C, Herrero-Fresneda I, Aran JM, Alperovich G, Vidal A, Grinyo JM: Regression of advanced diabetic nephropathy by hepatocyte growth factor gene therapy in rats. Diabetes 2004;53:1119-1127.

4 Ellis EN, Warady BA, Wood EG, Hassanein R, Richardson WP, Lane PH, Howard C, Kemp SF, Aceto T, Garibaldi L, Wiegmann TB, Savin VJ: Renal structural-functional relationships in early diabetes mellitus. Pediatr Nephrol 1997;11:584-591.

5 Kim HJ, Kong MK, Kim YC: Beneficial effects of Phellodendri Cortex extract on hyperglycemia and diabetic nephropathy in streptozotocin-induced diabetic rats. BMB Rep 2008;41:710-715.

6 Wahab NA, Schaefer L, Weston BS, Yiannikouris O, Wright A, Babelova A, Schaefer R, Mason RM: Glomerular expression of thrombospondin-1, transforming growth factor beta and connective tissue growth factor at different stages of diabetic nephropathy and their interdependent roles in mesangial response to diabetic stimuli. Diabetologia 2005;48:2650-2660.

7 Dronavalli S, Duka I, Bakris GL: The pathogenesis of diabetic nephropathy. Nat Clin Pract Endocrinol Metab 2008;4:444-452.

-8 Gross JL, de Azevedo MJ, Silveiro SP, Canani LH, Caramori ML, Zelmanovitz T: Diabetic nephropathy: diagnosis, prevention, and treatment. Diabetes Care 2005;28:164-176.

-9 Mauer SM, Steffes MW, Ellis EN, Sutherland DE, Brown DM, Goetz FC: Structural-functional relationships in diabetic nephropathy. J Clin Invest 1984;74:1143-1155.

10 Brownlee M: Biochemistry and molecular cell biology of diabetic complications. Nature 2001;414:813820.

11 Chow F, Ozols E, Nikolic-Paterson DJ, Atkins RC, Tesch GH: Macrophages in mouse type 2 diabetic nephropathy: correlation with diabetic state and progressive renal injury. Kidney Int 2004;65:116-128.

$\$ 12$ Ichinose K, Kawasaki E, Eguchi K: Recent advancement of understanding pathogenesis of type 1 diabetes and potential relevance to diabetic nephropathy. Am J Nephrol 2007;27:554-564.

$\checkmark 13$ Hill C, Flyvbjerg A, Rasch R, Bak M, Logan A: Transforming growth factor-beta2 antibody attenuates fibrosis in the experimental diabetic rat kidney. J Endocrinol 2001;170:647-651.

14 Dixon A, Maric C: 17beta-Estradiol attenuates diabetic kidney disease by regulating extracellular matrix and transforming growth factor-beta protein expression and signaling. Am J Physiol Renal Physiol 2007;293:F1678-1690.

$15 \mathrm{Oh} \mathrm{JH}, \mathrm{Ha}$ H, Yu MR, Lee HB: Sequential effects of high glucose on mesangial cell transforming growth factor-beta 1 and fibronectin synthesis. Kidney Int 1998;54:1872-1878.

16 Ziyadeh FN: Mediators of diabetic renal disease: the case for TGF- as the major mediator. J Am Soc Nephrol 2004;15:55S-57S.

17 Thorp ML: Diabetic nephropathy: common questions. Am Fam Physician 2005;72:96-99.

18 Barreira AL, Takiya CM, Castiglione RC, Maron-Gutierrez T, Barbosa CM, Ornellas DS, Verdoorn KS, Pascarelli BM, Borojevic R, Einicker-Lamas M, Leite M Jr, Morales MM, Vieyra A: Bone marrow mononuclear cells attenuate interstitial fibrosis and stimulate the repair of tubular epithelial cells after unilateral ureteral obstruction. Cell Physiol Biochem 2009;24:585-594. 


\section{Cellular Physiology Cell Physiol Biochem 2013;32:699-718 and Biochemistry \\ Castiglione et al.: Bone Marrow-Derived Mononuclear Cells and Diabetes}

19 Caldas HC, Fernandes IM, Gerbi F, Souza AC, Baptista MA, Ramalho HJ, Kawasakioyama RS, Goloni-Bertollo EM, Pavarino-Bertelli EC, Braile DM, Abbud-Filho M: Effect of whole bone marrow cell infusion in the progression of experimental chronic renal failure. Transplant Proc 2008;40:853-855.

20 Carvalho S, Cortez E, Stumbo AC, Thole A, Caetano C, Marques R, Pelajo-Machado M, Porto LC, Carvalho L: Laminin expression during bone marrow mononuclear cell transplantation in hepatectomized rats. Cell Biol Int 2008;32:1014-1018.

-21 Crovace A, Lacitignola L, Francioso E, Rossi G: Histology and immunohistochemistry study of ovine tendon grafted with cBMSCs and BMMNCs after collagenase-induced tendinitis. Vet Comp Orthop Traumatol 2008;21:329-336.

-22 Goel RK, Suri V, Suri A, Sarkar C, Mohanty S, Sharma MC, Yadav PK, Srivastava A: Effect of bone marrowderived mononuclear cells on nerve regeneration in the transection model of the rat sciatic nerve. J Clin Neurosci 2009;16:1211-1217.

23 Strauer BE, Brehm M, Zeus T, Kostering M, Hernandez A, Sorg RV, Kogler G, Wernet P: Repair of infarcted myocardium by autologous intracoronary mononuclear bone marrow cell transplantation in humans. Circulation 2002;106:1913-1918.

-24 Yoo KJ, Kim HO, Kwak YL, Kang SM, Jang YS, Lim SH, Hwang KC, Cho SW, Yang YS, Li RK, Kim BS: Autologous bone marrow cell transplantation combined with off-pump coronary artery bypass grafting in patients with ischemic cardiomyopathy. Can J Surg 2008;51:269-275.

25 Dolber PC, Spach MS: Conventional and confocal fluorescence microscopy of collagen fibers in the heart. J Histochem Cytochem 1993;41:465-469.

-26 Gordon S, Martinez FO: Alternative activation of macrophages: mechanism and functions. Immunity 2010;32:593-604.

27 Guerrero AR, Uchida K, Nakajima H, Watanabe S, Nakamura M, Johnson WE, Baba H: Blockade of interleukin- 6 signaling inhibits the classic pathway and promotes an alternative pathway of macrophage activation after spinal cord injury in mice. J Neuroinflammation 2012;9:40.

28 Redente EF, Orlicky DJ, Bouchard RJ, Malkinson AM : Tumor signaling to the bone marrow changes the phenotype of monocytes and pulmonary macrophages during urethane-induced primary lung tumorigenesis in A/J mice. Am J Pathol 2007;170:693-708.

-29 Hiragushi K, Wada J, Eguchi J, Matsuoka T, Yasuhara A, Hashimoto I, Yamashita T, Hida K, Nakamura Y, Shikata K, Minamino N, Kangawa K, Makino H: The role of adrenomedullin and receptors in glomerular hyperfiltration in streptozotocin-induced diabetic rats. Kidney Int 2004;65:540-550.

30 Palm F, Cederberg J, Hansell P, Liss P, Carlsson PO: Reactive oxygen species cause diabetes-induced decrease in renal oxygen tension. Diabetologia 2003;46:1153-1160.

-31 Samnegard B, Jacobson SH, Jaremko G, Johansson BL, Ekberg K, Isaksson B, Eriksson L, Wahren J, Sjoquist M: C-peptide prevents glomerular hypertrophy and mesangial matrix expansion in diabetic rats. Nephrol Dial Transplant 2005;20:532-538.

-32 Lee RH, Seo MJ, Reger RL, Spees JL, Pulin AA, Olson SD, Prockop DJ: Multipotent stromal cells from human marrow home to and promote repair of pancreatic islets and renal glomeruli in diabetic NOD/scid mice. Proc Natl Acad Sci U S A 2006;103:17438-17443.

-33 Ezquer FE, Ezquer ME, Parrau DB, Carpio D, Yañez AJ, Conget PA: Systemic administration of multipotent mesenchymal stromal cells reverts hyperglycemia and prevents nephropathy in type 1 diabetic mice. Biol Blood Marrow Transplant 2008;14:631-640.

-34 Ezquer F, Ezquer M, Simon V, Pardo F, Yañez A, Carpio D, Conget P: Endovenous administration of bone marrow-derived multipotent mesenchymal stromal cells prevents renal failure in diabetic mice. Biol Blood Marrow Transplant 2009;15:1354-1365.

-35 Gilbert RE, Cooper ME: The tubulointerstitium in progressive diabetic kidney disease: more than an aftermath of glomerular injury? Kidney Int 1999;56:1627-1637.

36 Tang SC, Leung JC, Lai KN: Diabetic tubulopathy: an emerging entity. Contrib Nephrol 2011;170:124-134.

-37 Tang SCW, Chan LYY, Leung JCK, Cheng AS, Chan KW, Lan HY, Lai KN: Bradykinin and high glucose promote renal tubular inflammation. Nephrol Dial Transplant 2009;25:698-710.

-38 Sharma K, Jin Y, Guo J, Ziyadeh FN: Neutralization of TGF-beta by anti-TGF-beta antibody attenuates kidney hypertrophy and the enhanced extracellular matrix gene expression in STZ-induced diabetic mice. Diabetes 1996;45:522-530. 


\section{Cellular Physiology Cell Physiol Biochem 2013;32:699-718 and Biochemistry \\ Castiglione et al.: Bone Marrow-Derived Mononuclear Cells and Diabetes}

-39 Sharma K, Ziyadeh FN: Hyperglycemia and diabetic kidney disease. The case for transforming growth factor-beta as a key mediator. Diabetes 1995;44:1139-1146.

40 Wolf G, Chen S, Ziyadeh FN: From the periphery of the glomerular capillary wall toward the center of disease: podocyte injury comes of age in diabetic nephropathy. Diabetes 2005;54:1626-1634.

-41 Suzawa H, Kikuchi S, Ichikawa K, Koda A: Inhibitory action of tranilast, an anti-allergic drug, on the release of cytokines and PGE2 from human monocytes-macrophages. Jpn J Pharmacol 1992;60:85-90.

-42 Akahori H, Ota T, Torita M, Ando H, Kaneko S, Takamura T: Tranilast prevents the progression of experimental diabetic nephropathy through suppression of enhanced extracellular matrix gene expression. J Pharmacol Exp Ther 2005;314:514-521.

43 de Vriese AS, Tilton RG, Elger M, Stephan CC, Kriz W, Lameire NH: Antibodies against vascular endthelial growth factor improve early renal dysfunction in experimental diabetes. J Am Soc Nephrol 2001;12:9931000.

44 Chen S, Kasama Y, Lee JS, Jim B, Marin M, Ziyadeh FN: Podocyte-derived vascular endothelial growth factor mediates the stimulation of alpha3(IV) collagen production by transforming growth factor-beta1 in mouse podocytes. Diabetes 2004;53:2939-2949.

45 Choudhary N, Ahlawat RS: Interleukin-6 and C-reactive protein in pathogenesis of diabetic nephropathy: new evidence linking inflammation, glycemic control, and microalbuminuria. Iran J Kidney Dis 2008;2:7279.

-46 Navarro-González JF, Mora-Fernández C, Muros de Fuentes M, García-Pérez J: Inflammatory molecules and pathways in the pathogenesis of diabetic nephropathy. Nat Rev Nephrol 2011;7:327-340.

-47 Balakumar P; Reddy J; Singh M: Do resident renal mast cells play a role in the pathogenesis of diabetic nephropathy? Mol Cell Biochem 2009;330:187-192.

-48 Galkina E, Ley K: Leukocyte recruitment and vascular injury in diabetic nephropathy. J Am Soc Nephrol 2006;17:368-377.

-49 Hartner A, Veelken R, Wittmann M, Cordasic N, Hilgers KF: Effects of diabetes and hypertension on macrophage infiltration and matrix expansion in the rat kidney. BMC Nephrol 2005;6:6.

50 Lim AKH, Ma FY, Nikolic-Paterson DJ, Thomas MC, Hurst LA, Tesch GH: Antibody blockade of c-fms suppresses the progression of inflammation and injury in early diabetic nephropathy in obese $\mathrm{db} / \mathrm{db}$ mice. Diabetologia 2009;52:1669-1679.

51 Tuttle KR: Linking metabolism and immunology: diabetic nephropathy is an inflammatory disease. J Am Soc Nephrol 2005;16:1537-1538.

52 Usui HK, Shikata K, Sasaki M, Okada S, Matsuda M, Shikata Y, Ogawa D, Kido Y, Nagase R, Yozai K, Ohga S, Tone A, Wada J, Takeya M, Horiuchi S, Kodama T, Makino H: Macrophage scavenger receptor-A-deficient mice are resistant against diabetic nephropathy through amelioration of microinflammation. Diabetes 2007;56:363-372.

-53 Mensah-Brown EPK, Obineche EN, Galadari S, Chandranath E, Shahin A, Ahmed I, Patel SM, Adem A: Streptozotocin-induced diabetic nephropathy in rats: the role of inflammatory cytokines. Cytokine 2005;31:180-190.

54 Sassy-Prigent C, Heudes D, Mandet C, Bélair MF, Michel O, Perdereau B, Bariéty J, Bruneval P: Early glomerular macrophage recruitment in streptozotocin-induced diabetic rats. Diabetes 2000;49:466-475.

55 Chow FY, Nikolic-Paterson DJ, Atkins RC, Tesch GH: Macrophages in streptozotocin-induced diabetic nephropathy: potential role in renal fibrosis. Nephrol Dial Transpl 2004;19:2987-2996.

56 Berbaum K, Shanmugam K, Stuchbury G, Wiede F, Körner H, Münch G: Induction of novel cytokines and chemokines by advanced glycation endproducts determined with a cytometric bead array. Cytokine 2008;41:198-203.

57 Mantovani A, Sica A, Sozzani S, Allavena P, Vecchi A, Locati M: The chemokine system in diverse forms of macrophage activation and polarization. Trends Immunol 2004;25:677-686.

58 Tesch GH: Macrophages and diabetic nephropathy. Semin Nephrol 2010;30:290-301.

-59 Furuta T, Saito T, Ootaka T, Soma J, Obara K, Abe K, Yoshinaga K: The role of macrophages in diabetic glomerulosclerosis. Am J Kidney Dis 1993;21:480-485.

60 Mantovani A, Sica A, Locati M: New vistas on macrophage differentiation and activation. Eur J Immunol 2007;37:14-16.

61 Biswas SK, Mantovani A: Macrophage plasticity and interaction with lymphocyte subsets: cancer as a paradigm. Nat Immunol 2010;11:889-896. 
Castiglione et al.: Bone Marrow-Derived Mononuclear Cells and Diabetes

62 Hao NB, Lü MH, Fan YH, Cao YL, Zhang ZR, Yang SM: Macrophages in tumor microenvironments and the progression of tumors [published online ahead of print Jun 19 2012]. Clin Dev Immunol 2012;2012:948098.

63 Ma LJ, Corsa BA, Zhou J, Yang H, Li H, Tang YW, Babaev VR, Major AS, Linton MF, Fazio S, Hunley TE, Kon V, Fogo AB: Angiotensin type 1 receptor modulates macrophage polarization and renal injury in obesity. Am J Physiol Renal Physiol 2011;300:F1203-1213.

64 Fujita E, Shimizu A, Masuda Y, Kuwahara N, Arai T, Nagasaka S, Aki K, Mii A, Natori Y, Iino Y, Katayama Y, Fukuda Y: Statin attenuates experimental anti-glomerular basement membrane glomerulonephritis together with the augmentation of alternatively activated macrophages. Am J Pathol 2010;177:1143-1154. Mills CD: M1 and M2 macrophages: oracles of health and disease. Crit Rev Immunol 2012;32:463-488.

66 Murray PJ, Wynn TA: Protective and pathogenic functions of macrophage subsets. Nat Rev Immunol 2011;11:723-737.

67 Wang Y, Wang YP, Zheng G, Lee VW, Ouyang L, Chang DH, Mahajan D, Coombs J, Wang YM, Alexander SI, Harris DC: Ex vivo programmed macrophages ameliorate experimental chronic inflammatory renal disease. Kidney Int 2007;72:290-299.

68 Wilson MS, Elnekave E, Mentink-Kane MM, Hodges MG, Pesce JT, Ramalingam TR, Thompson RW, Kamanaka M, Flavell RA, Keane-Myers A, Cheever AW, Wynn TA: IL-13Ralpha2 and IL-10 coordinately suppress airway inflammation, airway-hyperreactivity, and fibrosis in mice. J Clin Invest 2007;117:29412951.

69 Pesce JT, Ramalingam TR, Mentink-Kane MM, Wilson MS, El Kasmi KC, Smith AM, Thompson RW, Cheever AW, Murray PJ, Wynn TA: Arginase-1-expressing macrophages suppress Th2 cytokine-driven inflammation and fibrosis. PLoS Pathog 2009;5:e1000371.

70 Sinuani I, Averbukh Z, Gitelman I, Rapoport MJ, Sandbank J, Albeck M, Sredni B, Weissgarten J: Mesangial cells initiate compensatory renal tubular hypertrophy via IL-10-induced TGF-beta secretion: effect of the immunomodulator AS101 on this process. Am J Physiol Renal Physiol 2006;291:F384-394.

71 Wang Y, Tay YC, Harris DC: Proximal tubule cells stimulated by lipopolysaccharide inhibit macrophage activation. Kidney Int 2004;66:655-662.

-72 Nakajima H, Uchida K, Rodriguez Guerrero A, Watanabe S, Sugita D, Takeura N, Yoshida A, Long G, Wright $\mathrm{K}$, Johnson E, Baba H: Transplantation of mesenchymal stem cells promotes the alternative pathway of macrophage activation and functional recovery after spinal cord injury. J Neurotrauma 2012;29:16141625.

73 Dayan V, Yannarelli G, Billia F, Filomeno P, Wang XH, Davies JE, Keating A: Mesenchymal stromal cells mediate a switch to alternatively activated monocytes/macrophagesafter acute myocardial infarction. Basic Res Cardiol 2011;106:1299-1310. 